RESEARCH ARTICLE

\title{
Risk factors for neonatal sepsis in Lubumbashi, Democratic Republic of Congo: A retrospective case-control study
}

\author{
Adonis Muganza Nyenga ${ }^{1}$ Olivier Mukuku ${ }^{*}$ Janet Ziazia Sunguza $^{1}$ Amir N$^{\prime}$ simbo Assumani $^{1}$ Oscar Numbi Luboya $^{1,2}$ \\ Stanislas Okitotsho Wembonyama ${ }^{1}$ \\ ${ }^{1}$ Department of Pediatrics, Faculty of Medicine, University of Lubumbashi, Lubumbashi, Democratic Republic of Congo \\ ${ }^{2}$ Higher Institute of Medical Techniques, Lubumbashi, Democratic Republic of Congo
}

\section{Check for updates}

Correspondence to: Olivier Mukuku, Higher Institute of Medical Techniques, Lubumbashi, Democratic Republic of Congo; E-mail: oliviermukuku@yahoo.fr

Received: April 8, 2021;

Accepted: May 28, 2021;

Published: June 2, 2021

Citation: Nyenga AM, Mukuku O, Sunguza JZ, et al. Risk factors for neonatal sepsis in Lubumbashi, Democratic Republic of Congo: A retrospective casecontrol study. Theory Clin Pract Pediatr, 2021, 3(1) 63-70. https://doi.org/10.25082/TCPP.2021.01.003

Copyright: () 2021 Olivier Mukuku, et al. This is an open access article distributed under the terms of the Creative Commons Attribution License, which permits unrestricted use, distribution, and reproduction in any medium, provided the original author and source are credited

\section{(i) (8)}

\begin{abstract}
Purpose: Neonatal sepsis (NS) is a major cause of neonatal morbidity and mortality, particularly in developing countries. Delays in the identification and treatment of NS are the main contributors to the high mortality. This study aims to identify risk factors for NS in newborns in the two university hospitals in Lubumbashi, in the Democratic Republic of Congo. Methods: This hospital-based case-control study was carried out on 486 mother-newborn pairs using the systematic sampling method during November 2019 to October 2020. Data were analyzed using STATA software (version 15). Binary and multivariable logistic regression analyses were computed to identify the associated factors at $95 \%$ CI. Results: A total of 162 cases and 324 controls were included in this study. Multiple logistic regression analysis showed that the possible risk factors for NS in this study were low level of education (AOR $=9.16[2.23-37.67])$, maternal genitourinary tract infections $(\mathrm{AOR}=42.59$ [17.90-101.37]), premature rupture of membranes $(\mathrm{AOR}=19.95$ [7.27-54.76]), peripartum fever $(\mathrm{AOR}=26.25$ [2.31-297.83]), prolonged labor $(\mathrm{AOR}=14.16$ [3.88-51.71] $)$, cesarean section $(\mathrm{AOR}=3.57$ $[1.48-8.61])$, obstructed vaginal delivery $(A O R=13.40[1.32-136.19])$, birth weight $<1500$ grams $(\mathrm{AOR}=70.38$ [8.64-572.95]), and between 1500-2500 grams $(\mathrm{AOR}=7.90$ [3.04-20.52]) Conclusion: The study found that maternal and neonatal factors were strongly associated with the risk of developing NS. The present study suggests the possibility of routine assessment of sepsis in newborns born with the above characteristics.
\end{abstract}

Keywords: neonatal sepsis, maternal risk factors, neonatal risk factors, Lubumbashi

\section{Abbreviations}

\author{
95\% CI: $95 \%$ confidence interval \\ AOR: Adjusted odds ratio \\ COR: Crude odds ratio \\ DRC: Democratic Republic of Congo \\ NS: Neonatal sepsis \\ PROM: Premature rupture of membranes
}

\section{Introduction}

Neonatal sepsis (NS) is defined as a systemic inflammatory response syndrome in the presence or following a suspected or confirmed infection with or without associated bacteremia, documented by a positive blood culture during the first 28 days of life [1-3]. Globally, NS contributes significantly to neonatal morbidity and mortality and is a major public health challenge [4]. In 2019, according to global estimates, 2.4 (2.3 - 2.7) million newborns died within 28 days of birth [5]. The leading causes of neonatal death worldwide are infections (35\%), premature births (28\%), intrapartum complications (24\%) and asphyxia (23\%). In developing countries, sepsis is the most common cause of neonatal death each year and is probably responsible for 30-50\% of all neonatal deaths [3,4]. The survival of newborns is a matter of great concern to the world and specially to developing countries.

In Lubumbashi (in the Democratic Republic of Congo [DRC]), a recent study reported that prematurity $(50 \%)$, infection $(21 \%)$ and respiratory distress $(11.5 \%)$ are the most common causes of death in newborns [6]. There are a number of factors including maternal, fetal, and 
environmental factors that contribute to the occurrence of sepsis during neonatal life [7,8]. A study in Ethiopia also reported that maternal history of urinary tract infection or sexually transmitted infection, place of delivery, premature rupture of membranes (PROM), intrapartum fever, low Apgar score at the $5^{\text {th }}$ minute and so not crying immediately at birth have been identified as possible independent risk factors for NS [9]. The clinical signs in NS are nonspecific and can be found in several non-infectious clinical pictures. Thus, it is essential to identify the risk factors for NS early in order to allow diagnostic orientation and treatment aimed at reducing neonatal morbidity and mortality. The implementation of some clinical approaches is also effective in reducing the incidence of NS $[3,10]$.

Despite the considerable burden of NS in our context, no study has been conducted to identify associated factors of NS in newborns in Lubumbashi. Therefore, this study aims to identify risk factors for NS in newborns in the two university hospitals in Lubumbashi, in the DRC.

\section{Methods}

\subsection{Study design and settings}

This is a case-control study conducted in the two university hospitals of Lubumbashi (University Clinics and Sendwe Hospital) in Haut-Katanga province in the DRC from November 2019 to October 2020. These hospitals provide preventive, curative and promotional health care services to the population of the city of Lubumbashi and its surroundings and serve as a point of reference for medical training and health centers throughout the province.

\subsection{Study population}

The study included any newborn admitted to the neonatal intensive care units of these hospitals with the diagnosis of sepsis. In this study, NS is asserted when a medical diagnosis of the newborn is declared as 'neonatal sepsis' by the physician in the newborn's medical record. The recruitment of participants followed the oral consent of their mother. The control group consisted of newborns admitted for other pathology other than NS and who did not present with sepsis during their hospital stay. For each case, two controls were recruited within 24 hours of admission of the case.

Study participants included 486 mother-newborn pairs (including 162 cases and 324 controls) who were admitted to neonatal intensive care units of these two hospitals during the study period and consented to participate in the study. The study recruited newborns from birth to 28 days old. There were no newborns admitted two or more times during the study period.

\subsection{Data collection}

Data were collected using a prepared questionnaire (to collect study variables from the study population) after examining different literatures. This questionnaire was divided into three sections, including a section containing maternal socio-demographic characteristics, another section containing maternal history and a final section containing neonatal information. Two days of training were given to five data collectors (two pediatric resident physicians and two nurses) and a supervisor (pediatrician) prior to the start of data collection. The data were checked for completeness and accuracy during data collection. Close supervision of the trained data collectors was provided by the research team coordinator who provided on-site advice and feedback to the data collectors on a daily basis.

Admission diagnosis for newborns was obtained from the consultation sheet prepared by a pediatrician. Data collectors verify the diagnosis of NS with the medical record of the newborn being examined to make the final clinical diagnosis of NS before collecting the data. This clinical diagnosis was supplemented by the iterative determination of the $\mathrm{C}$-reactive protein to a significant threshold $\geq 20 \mathrm{mg} / \mathrm{L}$ from the 24th hour after suspicion of sepsis.

The World Health Organization criteria were applied to assess newborns for clinical sepsis. The clinical features for making a clinical diagnosis of NS used by these criteria are as follows: neurological disorders and behavioral changes (convulsions, coma, refusal to suck, irritability, hypotonia, etc.), respiratory distress (tachypnea, bradypnea, intercostal indrawing, expiratory groaning, etc.), modification of the coloration of integuments (jaundice, earthy complexion, central cyanosis, skin mottling, etc.), thermoregulation disorders (high temperature $\geq 38^{\circ} \mathrm{C}$, hypothermia $<35.5^{\circ} \mathrm{C}$ ), digestive disorders (severe abdominal distension, vomiting, diarrhea), one or more localized signs of infection $[11,12]$. 


\subsection{Data analysis}

Data were entered after defining the variables and analyzed using STATA software version 15.0. Variables were categorized and summarized in percentages and proportions. Binary analysis was performed. A crude odds ratio (COR) along with a $95 \%$ confidence interval (95\% CI) were used to determine the existence of an association between NS and various independent variables, including maternal and neonatal factors. Then, multivariate logistic regression was used to decrease the effect of confounding factors. An adjusted odds ratio (AOR) with a 95\% $\mathrm{CI}$ was used to measure the degree of association between the variables. Statistical significance was declared with a p-value less than 0.05 .

\subsection{Ethical considerations}

Ethics clearance was obtained from the medical ethics committee of the University of Lubumbashi (Approval number: UNILU/ CEM/ 038/ 2019). After explaining the purpose and possible benefit of the study, permission to collect data was obtained from medical directors and heads of neonatal intensive care units of these two hospitals. The privacy of the respondent and the confidentiality of information were ensured throughout the study procedure.

\section{Results}

In the present study, a total of 162 newborns who had sepsis (cases) with their mothers and 324 newborns who did not have sepsis (controls) with their mothers were included.

Table 1 presents risks associated with the different maternal socio-demographic variables studied, specifying the COR and the $95 \%$ CI for the bivariate analysis.

In bivariate analysis, the risk of NS in a newborn child increased significantly in women aged less than 20 years $(\mathrm{COR}=3.08)$, in single women $(\mathrm{COR}=3.20)$, in women of primary education level $(\mathrm{COR}=7.14)$ and secondary education level $(\mathrm{COR}=2.19)$.

Table 1 Unadjusted association between neonatal sepsis and socio-demographic characteristics of mothers

\begin{tabular}{|c|c|c|c|c|c|c|}
\hline \multirow{2}{*}{ Variable } & \multicolumn{4}{|c|}{ Neonatal sepsis } & \multirow{2}{*}{ Crude OR [95\% CI] } & \multirow{2}{*}{ p-value } \\
\hline & \multicolumn{2}{|c|}{ Yes $(n=162)$} & \multicolumn{2}{|c|}{ No $(n=324)$} & & \\
\hline \multicolumn{7}{|l|}{ Maternal age } \\
\hline$<20$ years & 28 & $17.28 \%$ & 20 & $6.17 \%$ & 3.08 [1.66-5.72] & 0.0002 \\
\hline $20-34$ years & 104 & $64.2 \%$ & 229 & $70.68 \%$ & Reference & \\
\hline$\geq 35$ years & 30 & $18.52 \%$ & 75 & $23.15 \%$ & 0.88 [0.54-1.43] & 0.606 \\
\hline \multicolumn{7}{|l|}{ Marital statut } \\
\hline Single & 15 & $9.26 \%$ & 10 & $3.09 \%$ & $3.20[1.41-7.30]$ & 0.003 \\
\hline Married & 147 & $90.74 \%$ & 314 & $96.91 \%$ & Reference & \\
\hline \multicolumn{7}{|l|}{ Parity } \\
\hline Primiparous & 49 & $30.25 \%$ & 89 & $27.47 \%$ & $1.14[0.76-1.73]$ & 0.522 \\
\hline Multiparous & 113 & $69.75 \%$ & 235 & $72.53 \%$ & Reference & \\
\hline \multicolumn{7}{|l|}{ Education level } \\
\hline Primary & 20 & $12.35 \%$ & 9 & $2.78 \%$ & $7.14[3.09-16.50]$ & $<0.0001$ \\
\hline Secondary & 81 & $50 \%$ & 119 & $36.73 \%$ & $2.19[1.46-3.27]$ & 0.0001 \\
\hline Higher/University & 61 & $37.65 \%$ & 196 & $60.49 \%$ & Reference & \\
\hline \multicolumn{7}{|l|}{ Profession } \\
\hline Student & 3 & $1.85 \%$ & 4 & $1.23 \%$ & $1.84[0.32-9.65]$ & 0.423 \\
\hline Functionary & 21 & $12.96 \%$ & 52 & $16.05 \%$ & Reference & \\
\hline Liberal & 29 & $17.9 \%$ & 60 & $18.52 \%$ & $1.20[0.61-2.35]$ & 0.6 \\
\hline Housewife & 109 & $67.28 \%$ & 208 & $64.2 \%$ & $1.30[0.74-2.26]$ & 0.358 \\
\hline
\end{tabular}

Regarding maternal history, six variables showed a significant overall effect on the risk of NS at the 5\% significance level in bivariate analysis (Table 2). The study revealed that chorioamnionitis $(\mathrm{COR}=28.01)$, peripartum fever $(\mathrm{COR}=18.89)$, genitourinary tract infections $(\mathrm{COR}=16.43), \mathrm{PROM}(\mathrm{COR}=14.84)$, prolonged labor $(\mathrm{COR}=13.56)$ and meconium amniotic fluid $(\mathrm{COR}=2.41)$ had a very significant association with the risk of NS $(\mathrm{p}<0.001)$.

Applying a bivariate analysis, the following neonatal variables showed a very highly significant effect on the risk of NS: gestational age $<37$ weeks $(\mathrm{COR}=14.42$ [7.08-29.39]; $\mathrm{p}$ $<0.0001)$, a birth weight $<1500(\mathrm{COR}=30.34$ [8.90-103.40]; $\mathrm{p}<0.0001)$ and between 1500 2499 grams $(\mathrm{COR}=7.97$ [4.80-13, 26]; $\mathrm{p}<0.0001)$, and an Apgar score $<7$ at the first minute $(\mathrm{COR}=6.35$ [3.25-12.44]; $\mathrm{p}<0.0001)$. The likelihood of developing NS was 2.95 times higher 
Table 2 Unadjusted association between neonatal sepsis and obstetric history

\begin{tabular}{|c|c|c|c|c|c|c|}
\hline \multirow{2}{*}{ Variable } & \multicolumn{4}{|c|}{ Neonatal sepsis } & \multirow{2}{*}{ Crude OR $[95 \% \mathrm{CI}]$} & \multirow{2}{*}{ p-value } \\
\hline & \multicolumn{2}{|c|}{ Yes $(n=162)$} & \multicolumn{2}{|c|}{ No $(n=324)$} & & \\
\hline \multicolumn{7}{|c|}{ Chorioamnionitis } \\
\hline Yes & 13 & $8.02 \%$ & 1 & $0.31 \%$ & $28.01[4.14-606.22]$ & $<0.00001$ \\
\hline No & 149 & $91.98 \%$ & 323 & $99.69 \%$ & Reference & \\
\hline \multicolumn{7}{|c|}{ Peripartum fever } \\
\hline Yes & 9 & $5.56 \%$ & 1 & $0.31 \%$ & $18.89[2.59-835.28]$ & 0.0003 \\
\hline No & 153 & $94.44 \%$ & 323 & $99.69 \%$ & Reference & \\
\hline \multicolumn{7}{|c|}{ Genitourinary tract infections } \\
\hline Yes & 69 & $42.59 \%$ & 14 & $4.32 \%$ & $16.43[8.84-30.52]$ & $<0.00001$ \\
\hline No & 93 & $57.41 \%$ & 310 & $95.68 \%$ & Reference & \\
\hline \multicolumn{7}{|c|}{$\begin{array}{l}\text { Premature rupture of } \\
\text { membranes }\end{array}$} \\
\hline Yes & 52 & $32.1 \%$ & 10 & $3.09 \%$ & $14.84[7.29-30.21]$ & $<0.00001$ \\
\hline No & 110 & $67.9 \%$ & 314 & $96.91 \%$ & Reference & \\
\hline \multicolumn{7}{|c|}{ Prolonged labor } \\
\hline Yes & 33 & $20.37 \%$ & 6 & $1.85 \%$ & $13.56[5.55-33.13]$ & $<0.00001$ \\
\hline No & 129 & $79.63 \%$ & 318 & $98.15 \%$ & Reference & \\
\hline \multicolumn{7}{|c|}{ Meconium amniotic fluid } \\
\hline Yes & 41 & $25.31 \%$ & 40 & $12.35 \%$ & $2.41[1.48-3.91]$ & 0.0003 \\
\hline No & 121 & $74.69 \%$ & 284 & $87.65 \%$ & Reference & \\
\hline \multicolumn{7}{|c|}{ Hypertension } \\
\hline Yes & 15 & $9.26 \%$ & 32 & $9.88 \%$ & $0.93[0.49-1.77]$ & 0.828 \\
\hline No & 147 & $90.74 \%$ & 292 & $90.12 \%$ & Reference & \\
\hline
\end{tabular}

in babies born by cesarean section $(\mathrm{COR}=2.95$ [1.79-4.85]; $\mathrm{p}<0.0001)$ than in newborns born eutocically vaginally (Table 3 ).

Table 3 Unadjusted association between neonatal sepsis and neonatal characteristics

\begin{tabular}{|c|c|c|c|c|c|c|}
\hline \multirow{2}{*}{ Variable } & \multicolumn{4}{|c|}{ Neonatal sepsis } & \multirow{2}{*}{ Crude OR $[95 \% \mathrm{CI}]$} & \multirow{2}{*}{ p-value } \\
\hline & \multicolumn{2}{|c|}{ Yes $(n=162)$} & \multicolumn{2}{|c|}{ No $(n=324)$} & & \\
\hline \multicolumn{7}{|l|}{ Gestational age } \\
\hline$<37$ weeks & 51 & $31.48 \%$ & 10 & $3.09 \%$ & $14.42[7.08-29.39]$ & $<0.0001$ \\
\hline$\geq 37$ weeks & 111 & $68.52 \%$ & 314 & $96.91 \%$ & Reference & \\
\hline \multicolumn{7}{|l|}{$\operatorname{Sex}$} \\
\hline Male & 84 & $51.85 \%$ & 174 & $53.7 \%$ & $0.93[0.64-1.35]$ & 0.699 \\
\hline Female & 78 & $48.15 \%$ & 150 & $46.3 \%$ & Reference & \\
\hline \multicolumn{7}{|l|}{ Birth weight } \\
\hline$<1500$ grams & 24 & $14.81 \%$ & 3 & $0.93 \%$ & $30.34[8.90-103.40]$ & $<0.0001$ \\
\hline $1500-2499$ grams & 61 & $37.65 \%$ & 29 & $8.95 \%$ & $7.97[4.80-13.26]$ & $<0.0001$ \\
\hline$\geq 2500$ grams & 77 & $47.53 \%$ & 292 & $90.12 \%$ & Reference & \\
\hline \multicolumn{7}{|l|}{ Apgar score at the first minute } \\
\hline$<7$ & 34 & $20.99 \%$ & 13 & $4.01 \%$ & $6.35[3.25-12.44]$ & $<0.0001$ \\
\hline$\geq 7$ & 128 & $79.01 \%$ & 311 & $95.99 \%$ & Reference & \\
\hline \multicolumn{7}{|l|}{ Mode of delivery } \\
\hline Obstructed vaginal delivery & 4 & $2.47 \%$ & 4 & $1.23 \%$ & $2.45[0.45-13.39]$ & 0.195 \\
\hline Cesarean section & 42 & $25.93 \%$ & 35 & $10.8 \%$ & $2.95[1.79-4.85]$ & $<0.0001$ \\
\hline Eutocical delivery & 116 & $71.6 \%$ & 285 & $87.96 \%$ & Reference & \\
\hline
\end{tabular}

Many variables that were significantly associated with NS during the bivariate analysis were not significantly associated during the multivariate analysis. Education level, mode of delivery, PROM, peripartum fever, genitourinary tract infections, prolonged labor, and birth weight were significantly associated with NS in multiple logistic regression (Table 4).

Educational level was independently associated with NS. Newborns of mothers with primary education level were more likely to develop NS than newborns of mothers with higher education level $($ AOR $=9.16)$.

The present study showed that newborns born to mothers who had genitourinary tract infections during pregnancy were 43 times more likely to develop sepsis compared to newborns born to mothers who had not had genitourinary tract infections during pregnancy $(\mathrm{AOR}=$ 42.59).

Likewise, an increased risk of NS was noted in newborns of mothers with a history of peripartum fever compared to newborns of mothers without peripartum fever ( $A O R=26.25$ ). The likelihood of NS independently increased in newborns whose mothers had PROM (AOR = 
19.95) and in newborns whose mothers had prolonged labor (AOR =14.16). Newborns born by cesarean section and obstructed vaginal delivery were 13 times and 3 times more likely to develop sepsis, respectively, than newborns born via the eutocical delivery (AOR $=13.40$ and $\mathrm{AOR}=3.57$ ).

Birth weight has been shown to be significantly associated with the risk of developing NS. The odds of having NS in infants $<1500$ grams and 1500-2500 grams were 70 and 8 times higher, respectively, than in infants $\geq 2500$ grams ( $A O R=70.38$ and $A O R=7.90$ ).

Table 4 Multiple logistic regression of risk factors for neonatal sepsis in newborns in Lubumbashi

\begin{tabular}{|c|c|c|c|c|}
\hline Variable & AOR & $\mathrm{t}$-value & p-value & {$[95 \% \mathrm{CI}]$} \\
\hline \multicolumn{5}{|l|}{ Maternal age } \\
\hline$<20$ years & 1.04 & 0.06 & 0.954 & {$[0.27-3.95]$} \\
\hline $20-34$ years & Reference & & & \\
\hline$\geq 35$ years & 0.807 & -0.50 & 0.619 & {$[0.35-1.88]$} \\
\hline \multicolumn{5}{|l|}{ Marital statut } \\
\hline Married & Reference & & & \\
\hline Single & 0.21 & -1.96 & 0.05 & {$[0.04-1.00]$} \\
\hline \multicolumn{5}{|l|}{ Education level } \\
\hline Primary & 9.16 & 3.07 & 0.002 & {$[2.23-37.67]$} \\
\hline Secondary & 1.53 & 1.15 & 0.250 & {$[0.74-3.15]$} \\
\hline Higher / University & Reference & & & \\
\hline \multicolumn{5}{|l|}{ Premature rupture of membranes } \\
\hline No & Reference & & & \\
\hline Yes & 19.95 & 5.81 & $<0.00001$ & {$[7.27-54.76]$} \\
\hline \multicolumn{5}{|l|}{ Genitourinary tract infections } \\
\hline No & Reference & & & \\
\hline Yes & 42.59 & 8.48 & $<0.00001$ & [17.90-101.37] \\
\hline \multicolumn{5}{|l|}{ Prolonged labor } \\
\hline No & Reference & & & \\
\hline Yes & 14.16 & 4.01 & $<0.00001$ & {$[3.88-51.71]$} \\
\hline \multicolumn{5}{|l|}{ Peripartum fever } \\
\hline No & Reference & & & \\
\hline Yes & 26.25 & 2.64 & 0.008 & [2.31-297.83] \\
\hline \multicolumn{5}{|l|}{ Chorioamnionitis } \\
\hline No & Reference & & & \\
\hline Yes & 5.85 & 1.42 & 0.155 & {$[0.51-66.68]$} \\
\hline \multicolumn{5}{|l|}{ Meconium amniotic fluid } \\
\hline No & Reference & & & \\
\hline Yes & 1.12 & 0.24 & 0.812 & {$[0.45-2.76]$} \\
\hline \multicolumn{5}{|l|}{ Gestational age } \\
\hline$<37$ weeks & 1.64 & 0.72 & 0.469 & {$[0.43-6.30]$} \\
\hline$\geq 37$ weeks & Reference & & & \\
\hline \multicolumn{5}{|l|}{ Mode of delivery } \\
\hline Eutocical delivery & Reference & & & \\
\hline Obstructed vaginal delivery & 13.40 & 2.19 & 0.028 & [1.32-136.19] \\
\hline Cesarean section & 3.57 & 2.83 & 0.005 & {$[1.48-8.61]$} \\
\hline \multicolumn{5}{|l|}{ Birth weight } \\
\hline$<1500$ grams & 70.38 & 3.98 & $<0.00001$ & {$[8.64-572.95]$} \\
\hline 1500-2499 grams & 7.90 & 4.24 & $<0.00001$ & {$[3.04-20.52]$} \\
\hline$\geq 2500$ grams & Reference & & & \\
\hline \multicolumn{5}{|l|}{ Apgar score at the first minute } \\
\hline$<7$ & 1.31 & 0.39 & 0.697 & {$[0.34-4.98]$} \\
\hline$\geq 7$ & Reference & & & \\
\hline
\end{tabular}

\section{Discussion}

The present study made it possible to establish the independent nature of the risk factors for NS in Lubumbashi. The factors identified are low educational level, PROM, maternal genitourinary tract infections during pregnancy, peripartum fever, prolonged or obstructed labor cesarean section, and low birth weight $(<2500$ grams $)$.

Low educational level was a significant risk factor for NS. This agrees with the conclusions of Shah et al. [13] who observed that maternal literacy was linked to NS. Compared to their illiterate counterparts, women with a higher educational level are more likely to better understand childcare and hygiene issues [14], seek health care and influence content of their care through their requests and adherence to the opinion of the healthcare worker [15].

In the present study, $42.6 \%$ of cases were born to mothers who had a history of genitourinary tract infections during pregnancy with a higher likelihood of developing sepsis compared to 
newborns to mothers who had no genitourinary tract infection (AOR $=42.6$ ). This finding is consistent with those made by several authors who have reported that maternal genitourinary tract infections were an important factor in the development of NS [3, 7, 9, 16,17]. This could be explained by the fact that, if they are not treated during the third trimester of pregnancy, maternal genitourinary tract infections can be associated with NS following colonization of the birth canal by infectious agents $[9,16]$. In addition, they are also involved in the occurrence of PROM, through the secretion of proteinases which increase the degradation of the extracellular matrix of fetal membranes, which explains their weakening [15].

PROM and prolonged labor increase the risk of microorganisms rising from the birth canal to the amniotic sac and the fetus, frequently leading to sepsis [9]. Thus, newborns are at risk of ascending infection which would be caused by vertical transmission from an infected mother. In the present study, PROM and prolonged labor were found to be significant independent factors of NS. Our results showed that newborns to mothers with a history of PROM had a 20-fold increased risk of developing NS. This finding was consistent with those observed in previous studies conducted in different regions of the world $[8,9,11,18]$. Birth is a period of sudden transition from a highly protected environment (amniotic cavity) to exposure to a wide range of pathogens ex utero. During parturition, the newborn comes in direct contact with maternal blood or genital secretions, and neonatal infections can result, especially with prolonged or premature rupture of membranes [19].

Prolonged labor $(\mathrm{AOR}=14.16[3.88-51.71])$ and obstructed vaginal delivery $(\mathrm{AOR}=13.40$ [1.32-136.19]) were predictors of NS in the present study. Similarly, a review of the literature by Abate et al. [17] reported that prolonged or obstructed labor was associated with NS. As demonstrated in a Ugandan study, this finding could be explained by the fact that the number of hours of labor was a significant independent risk factor for vaginal colonization in women with prolonged or obstructed labor [20].

In the present study, newborns born to mothers who had a peripartum fever were 26 times more likely to develop sepsis than newborns born to mothers who did not have a peripartum fever. Peripartum fever showed a significant effect on the development of NS. This is consistent with previous studies in Ethiopia and Pakistan [9,21]. Intrapartum fever indicates maternal infections that are frequently transmitted to the newborn in utero or during passage through the duct, which usually causes early sepsis $[9,22]$.

As found in previous studies [18,23,24], our study also showed that the likelihood of developing sepsis in newborns born by cesarean section was more likely to develop sepsis than their counterparts. Contrary to our results, Siakwa et al. [25] found that the mode of delivery was not statistically associated with NS. Newborns born by cesarean section are not exposed to vaginal and fecal bacteria, but are more exposed to nosocomial infections; they often experience extended hospital stays and late initiation of breastfeeding $[18,26]$. According to Mugadza et al. [27], the late initiation of breastfeeding after cesarean section would deprive the newborn of the protective effect of colostrum against various pathogens and its ability to provide immunity to the newborn. This would make these newborns vulnerable to nosocomial infections due to their reduced immunological profile.

Our study describes a strong association between low birth weight and NS. The multivariate analysis of risk factors for neonatal sepsis proven by Geyesus et al. [23], demonstrated a statistically significant association with lo w birth weight. Similar results have also been observed in other previous studies [25,28]. At birth, a newborn's immune system remains immature. Some protection is provided by maternal antibodies $(\mathrm{IgG})$ crossing the placenta. This process is less complete in low birth weight, especially if it is premature. In addition, premature infants are more likely to require invasive procedures (umbilical catheterization and intubation) and have a long stay. Poor practices and failure to follow guidelines by healthcare professionals during resuscitation can predispose the newborn to a higher risk of developing sepsis.

The results of the present study should be interpreted with certain limitations. First, due to the nature of the case-control study, the temporal relationship of events between the explanatory variables and NS cannot be determined. Recall bias also has potential limitations that could have affected the accuracy of the information. Second, given that the study is carried out among newborns admitted to tertiary hospitals (mainly in urban settings), the results may not be generalizable to the general population. Finally, lack of microbiology, diagnosis by different caregivers could lead to errors in the identification of cases and controls in the study.

\section{Conclusion}

This study established a strong association between NS and the following: low level of education, PROM, maternal genitourinary tract infections during pregnancy, peripartum fever, prolonged or obstructed labor, cesarean section, and low birth weight. The present study suggests 
the possibility of routine assessment of sepsis in newborns born with the above characteristics. Thus, to help identify risk factors and appropriate interventions to reduce the occurrence of NS, it is important to encourage the use of antenatal care services by mothers and to promote obstetric-pediatric collaboration.

\section{Competing interests}

The authors declare that they have no competing interests.

\section{References}

[1] Goldstein B, Giroir B and Randolph A. International pediatric sepsis consensus conference: definitions for sepsis and organ dysfunction in pediatrics. Pediatric Critical Care Medicine, 2005, 6(1): 2-8. https://doi.org/10.1097/01.PCC.0000149131.72248.E6

[2] Wynn JL. Defining neonatal sepsis. Current opinion in pediatrics, 2016, 28(2): 135-140. https://doi.org/10.1097/MOP.0000000000000315

[3] Agnche Z, Yeshita HY and Gonete KA. Neonatal Sepsis and Its Associated Factors Among Neonates Admitted to Neonatal Intensive Care Units in Primary Hospitals in Central Gondar Zone, Northwest Ethiopia, 2019. Infection and Drug Resistance, 2020, 13: 3957-3967. https://doi.org/10.2147/IDR.S276678

[4] Getabelew A, Aman M, Fantaye E, et al. Prevalence of neonatal sepsis and associated factors among neonates in neonatal intensive care unit at selected governmental hospitals in Shashemene Town Oromia Regional State, Ethiopia, 2017. International Journal of Pediatrics, 2018, 2018. https://doi.org/10.1155/2018/7801272

[5] UN Inter-agency Group for Child Mortality Estimation. Levels and Trends in Child Mortality: 2020 Report. United Nations Children's Fund (UNICEF), World Health Organization (WHO), World Bank Group, and United Nations Population Division, 2020.

https://www.un.org/development/desa/pd/news/levels-and-trends-child-mortality-2020-report

[6] Nyenga AM, Malonda BN, Abdala AK, et al. Trends in Neonatal Mortality in Lubumbashi (Democratic Republic of Congo) from 2011 to 2018. Clinical Pediatrics, 2019, 2: 1017.

[7] Nyenga A, Mukuku O, Mutombo AM, et al. Infections néonatales : quelle est la place des antécédents obstétricaux dans la prévention du risque? The Pan African Medical Journal, 2014, 19: 133. https://doi.org/10.11604/pamj.2014.19.133.4432

[8] Murthy S, Godinho MA, Guddattu V, et al. Risk factors of neonatal sepsis in India: A systematic review and meta-analysis. PLoS ONE, 2019, 14(4): e0215683. https://doi.org/10.1371/journal.pone.0215683

[9] Gebremedhin D, Berhe H and Gebrekirstos K. Risk Factors for Neonatal Sepsis in Public Hospitals of Mekelle City, North Ethiopia, 2015: Unmatched Case Control Study. PLoS ONE, 2016, 11(5): e0154798.

https://doi.org/10.1371/journal.pone.0154798

[10] Jabiri A, Wella HL, Semiono A, et al. Prevalence and factors associated with neonatal sepsis among neonates in Temeke and Mwananyamala Hospitals in Dar es Salaam, Tanzania. Tanzania Journal of Health Research, 2016, 18(4): 1-7.

[11] Kayom VO, Mugalu J, Kakuru A, et al. Burden, and factors associated with clinical neonatal sepsis in urban Uganda: a community cohort study. BMC Pediatr, 2018, 18(1): 355 https://doi.org/10.1186/s12887-018-1323-4

[12] World Health Organisation and UNICEF. Handbook: IMCI integrated management of childhood illness. Geneva: WHO. 2005.

[13] Shah GS, Budhathoki S, Das BK, et al. Risk factors in early neonatal sepsis. Kathmandu University Medical Journal, 2006, 4(14): 187-191.

[14] Onyedibe KI, Utoh-Nedosa AU, Okolo MO, et al. Impact of socioeconomic factors on neonatal sepsis in Jos, Nigeria. Jos Journal of Medicine, 2011, 6(2).

[15] Ilunga PM, Mukuku O, Mawaw PM, et al. Risk factors for low birth weight in Lubumbashi, Democratic Republic of the Congo. Médecine et santé tropicales, 2016, 26(4): 386-390. https://doi.org/10.1684/mst.2016.0607

[16] Woldu MA, Guta MB, Lenjisa JL, et al. Assessment of the incidence of neonatal sepsis, its risk factors, antimicrobial use and clinical outcomes in Bishoftu General Hospital, Neonatal Intensive Care Unit, Debrezeit-Ethiopia. Pediat Therapeut, 2014, 4: 214. https://doi.org/10.5455/2349-3291.ijcp20141102

[17] Abate BB, Kasie AM, Reta MA, et al. Neonatal sepsis and its associated factors in East Africa: a systematic review and meta-analysis. International Journal of Public Health, 2020, 65: 1623-1633. https://doi.org/10.1007/s00038-020-01489-x

[18] Adatara P, Afaya A, Salia SM, et al. Risk Factors Associated with Neonatal Sepsis: A Case Study at a Specialist Hospital in Ghana. The Scientific World Journal, 2019, 2019: 1-8. https://doi.org/10.1155/2019/9369051 
[19] Bhargava A, Gur R, Kaur H, et al. Risk factors and outcome analysis of gram-positive and gramnegative neonatal sepsis: a case-control study. Canadian Journal of Infection Control, 2017, 32(2): 98-103.

[20] Ngonzi J, Bebell LM, Bazira J, et al. Risk factors for vaginal colonization and relationship between bacterial vaginal colonization and in-hospital outcomes in women with obstructed labor in a Ugandan regional referral hospital. International Journal of Microbiology, 2018, 2018: 1-7. https://doi.org/10.1155/2018/6579139

[21] Alam MM, Saleem AF, Shaikh AS, et al. Neonatal sepsis following prolonged rupture of membrane in a tertiary hospital in Karachi Pakistan. The Journal of Infection in Developing Countries, 2014, 8(1): 067-073.

https://doi.org/10.3855/jidc.3136

[22] Hasan MS and Mahmood CB. Predictive values of risk factors in neonatal sepsis. Journal of Bangladesh College of Physicians and Surgeons, 2011, 29: 187-195. https://doi.org/10.3329/jbcps.v29i4.11324

[23] Geyesus T, Moges F, Eshetie S, et al. Bacterial etiologic agents causing neonatal sepsis and associated risk factors in Gondar, Northwest Ethiopia. BMC Pediatrics, 2017, 17: 137. https://doi.org/10.1186/s12887-017-0892-y

[24] Aamir M, Ali E, Hamouda M, et al. Prevalence of multi drug resistant bacteria causing late-onset neonatal sepsis. International Journal of Current Microbiology and Applied Sciences, 2015, 4(5): 172-190.

[25] Siakwa M, Kpikpitse D, Mupepi S, et al. Neonatal sepsis in rural Ghana: A case control study of risk factors in a birth cohort. International Journal of Research in Medical and Health Sciences, 2014 4(5): 72-83.

[26] Bager P, Simonsen J, Ethelberg S, et al. Cesarean delivery and risk of intestinal bacterial infection. The Journal of Infectious Diseases, 2010, 201(6): 898-902. https://doi.org/10.1086/650998

[27] Mugadza G, Zvinavashe M, Gumbo FZ, et al. Early breastfeeding initiation and incidence of neonatal sepsis in Chipinge District Zimbabwe. International Journal of Contemporary Pediatrics, 2018, 5(1): $1-5$. https://doi.org/10.18203/2349-3291.ijcp20175564

[28] Araújo BC and Guimarães H. Risk factors for neonatal sepsis: an overview. Journal of Pediatric and Neonatal Individualized Medicine, 2020, 9(2): e090206. 